\title{
Factors affecting consumers' decisions on the use of nutraceuticals: A systematic
}

review.

Siew Li Teoh ${ }^{1}$, Surachat Ngorsuraches ${ }^{2}$, Nai Ming Lai ${ }^{3,4}$, Mukdarut Bangpan ${ }^{5}$, Nathorn Chaiyakunapruk ${ }^{1,4,6,7 *}$

${ }^{1}$ School of Pharmacy, Monash University Malaysia, Selangor, Malaysia;

${ }^{2}$ Department of Pharmacy Practice, College of Pharmacy and Allied Health Professions, South Dakota State University, Brookings, USA;

${ }^{3}$ School of Medicine, Taylor's University Malaysia, Selangor, Malaysia;

${ }^{4}$ Synthesis in Population, Implementation and Clinical Outcomes (PICO), Health and Well-being Cluster, Global Asia in the 21st Century (GA21) Platform, Monash University Malaysia, Bandar Sunway, Selangor, Malaysia

${ }^{5}$ Evidence for Policy and Practice Information and Coordinating (EPPI)-Centre, Social Science Research Unit, UCL Institute of Education, University College London, London, UK;

${ }^{6}$ Center of Pharmaceutical Outcomes Research (CPOR), Department of Pharmacy Practice, Faculty of Pharmaceutical Sciences, Naresuan University, Phitsanulok, Thailand;

${ }^{7}$ School of Pharmacy, University of Wisconsin, Madison, USA;

\section{*Corresponding author:}

Nathorn Chaiyakunapruk, PharmD, PhD

Center of Pharmaceutical Outcomes Research (CPOR),

Department of Pharmacy Practice,

Faculty of Pharmaceutical Sciences,

Naresuan University, Phitsanulok, 65000 Thailand

Tel: (+6655) 961826

E-mail: nathorn.chaiyakunapruk@monash.edu

Word Counts: Abstract (185), Manuscript (3,190), Reference (103)

Keywords: Nutraceuticals, Dietary Supplement, Functional Food, Consumer, Systematic Review, Motivation, Barrier 


\begin{abstract}
There is a high and increasing global prevalence of nutraceuticals use. This study aims to systematically review and critically appraise all available evidence to identify the factors affecting consumers' decisions in taking nutraceuticals. Questionnaire, interview or focus group studies which directly reported factors affecting consumers' decisions in using nutraceuticals were included. A thematic synthesis method was employed to synthesis the findings from the included studies. Out of the 76 studies included, the key factors identified as the most important factors motivating consumers to take nutraceuticals were the perceived health benefits and safety of nutraceuticals, as well as the advice from healthcare professionals, friends and family. The identified barriers to take nutraceuticals were a lack of belief in the health benefit of nutraceuticals, the high cost of nutraceuticals and consumers' lack of knowledge about nutraceuticals. As a chief course of recommendation for the use of nutraceuticals, healthcare professionals should strive to utilise reliable information from clinical evidence to help consumers in making an informed decision in using nutraceuticals. Future studies should explore the possible ways to improve channelling clinical evidence information of nutraceuticals to the public.
\end{abstract}




\section{INTRODUCTION}

Nutraceuticals is a broad term defined as "any substance that may be considered a food or part of a food, and provides medical or health benefits, including the prevention and treatment of disease" (The Foundation for Innovative Medicine, 1992). As there is no internationally recognised standard on what constitutes nutraceuticals (Aronson, 2017), in align with the definition, the coverage of nutraceuticals include dietary supplements (DS) (U.S. Food and Drug Administration, 2015) and functional foods (Hasler et al., 2004) as how the two components have been defined according to the United States (US) Food and Drug Administration (U.S. Food and Drug Administration, 2015) and the American Dietetic Association (Hasler et al., 2004) (Appendix S1). According to the most recent study, 52\% of the US population were using DS from 1999 through 2012 (Kantor et al., 2016). Moreover, the number of DS in the US DS market has increased tremendously from 4,000 in 1994 to 55,000 in 2012 (Kuszak et al., 2016), with a USD32 billion sales in 2012 (Garcia-Cazarin et al., 2014). A similar trend of DS consumption has also been observed in the United Kingdom, European countries and Korea (Rautiainen et al., 2016a).

Despite the high prevalence of nutraceuticals use, high-quality studies (including clinical trials and observational studies), showed no or minimal health benefits of nutraceuticals. These include National Institute of Health (NIH)-funded studies of multivitamins for cancer and cardiovascular disease prevention (Neuhouser et al., 2009), echinacea for common cold treatment (Turner et al., 2005), St John's wort for depression (Shelton et al., 2001), and selenium and vitamin E for cancer prevention (Lippman et al., 2009). At the same time, increasing evidence was reported on the harmfulness of DSs, for example, the increased risk of lung cancer among smokers when beta-carotene supplements were taken at a high-dose (Tanvetyanon and Bepler, 2008), and the increased mortality risk associated with antioxidants intake (Bjelakovic et al., 2004). 
Studies suggested that the reasons why consumers continue to use DSs despite a lack of supporting clinical evidence were consumers' lack of awareness on the clinical evidence (Cohen, 2016), a lax regulation for nutraceuticals companies to sell nutraceuticals, and to advertise with health claims (Cohen, 2016, Starr, 2015), a lack of appropriate consultation with healthcare professionals with updated clinical evidence information (Cohen, 2016).

In evidence, many studies have been conducted to investigate consumers' view on the factors affecting their decisions in using nutraceuticals, but there is a lack of comprehensive summary with critical appraisal of existing studies. One systematic review (Mogendi et al., 2016) had a broad topic of general food choice with no outcomes directly related to the intention of consumers in using nutraceuticals. Therefore, the objective of this study is to systematically review and critically appraise all the available evidence to identify the factors affecting consumers' decisions in using nutraceuticals from consumers' perspective.

\section{METHODS}

This systematic review was reported in accordance with the Enhancing Transparency in Reporting the Synthesis of Qualitative Research (ENTREQ) guidelines, a guideline for reporting the synthesis of qualitative research (Tong et al., 2012).

\section{Data Sources and Search Strategy}

We pre-planned the searching approach and performed electronic searches for relevant articles published from inception to 28th March 2017. We searched MEDLINE, Embase, PsycInfo, Allied and Complementary Medicine Database (AMED), Cinahl Plus and Scopus databases. The search strategy was a range of combined related keywords consisted of "nutraceuticals", “factor", "qualitative method", and "consumption”. The full search strategy can be found in Appendix S2. Only English articles were searched. In addition, 
bibliographies of relevant articles were examined to identify potential studies not indexed in the aforementioned databases.

\section{Study Selection}

Studies were included if they i) were original research papers with empirical data collected through questionnaire, interview or focus group, ii) have explored at least one factor which could affect or not affect consumers' decisions on the use of nutraceuticals and iii) those factors must be stated from the consumers. Studies were excluded if i) the participants belong to the group at risk of deficiencies where dietary supplementation is recognised to help meet requirements (i.e. pregnant women and malnourished group (Rautiainen et al., 2016b)), ii) the topic of the study was assessed to be on the broad topic of complementary and alternative medicines (CAM) or general food choice as they are not specific to nutraceuticals. Initially, title and abstract of articles were screened to identify potentially relevant studies. Thereafter, full-text of relevant studies were retrieved and reviewed.

\section{Data Extraction and Quality Assessment}

The data extracted included study design, participant characteristics, and nutraceuticals type using a standardised data extraction sheet. For qualitative studies, Joanna Briggs Institute critical appraisal tools for qualitative research was employed to assess a) the congruity between i) research question and methodology, ii) analysis and interpretation of data, iii) flow of data analysis and conclusion, b) the influence of the researcher on the research, c) whether has the study been ethically approved by appropriate body; where a total of 10 criteria were assessed with 1 score was given for each fulfilled criterion and 0 score for unclear or unfulfilled criterion (Lockwood et al., 2015). For questionnaire studies, as there was no standardised quality assessment tool, we used only the 'sample selection' part of NewcastleOttawa Scale adapted for cross-sectional studies (Herzog et al., 2013) to assess the 
representativeness of the sample and the sample size; a score of 1 was given for each fulfilled criterion and 0 for unclear or unfulfilled criterion (Appendix S3).

\section{Data Analysis}

We identified the components of factors affecting consumers' decisions on the use of nutraceuticals through a thorough review of paper using thematic synthesis method (Thomas and Harden, 2008). Initially, included studies were studied line-by-line and the emerged themes were coded (first order) by SLT and MB with related-factors affecting the decision of consumers in taking nutraceuticals. The similarities and differences between the first order codes were reviewed and they were grouped with newly created codes (second and third order) into a hierarchical tree structure by SLT, SN, NML, MB and NC. This process resulted in three layers of coding to organise all the descriptive codes. The identified codes were analysed as factors affecting consumers' decision on the use of nutraceuticals in detail. Any disagreement was resolved by discussion and consensus.

\section{Assessment of Confidence of Findings}

We used the Confidence in the Evidence from Reviews of Qualitative Research (CERQual) approach (Lewin et al., 2015) to assess the confidence of findings. The assessment consisted of four domains including methodological quality of primary studies, the relevance of the body of evidence contributing to the context of review question, the coherence of the review findings, and the adequacy of data supporting the review findings.

\section{RESULTS}

\section{Study Selection}

Our search yielded a total of 5,679 potential articles from electronic databases and 8 from bibliographies of relevant articles. Duplicates of 1,339 articles were removed. Of the 
remaining 4,348 studies screened, only 294 were relevant and retrieved to be reviewed in full-text. During the full-text screening, only 76 studies met the inclusion criteria. The excluded studies were not examining the factors influencing consumers' decisions to use nutraceuticals $(n=99)$, factors not directly obtained from participants $(n=54)$, not nutraceuticals $(n=33)$, general CAM $(n=18)$, participants group with essential need of DS $(n=8)$, not primary data $(n=3)$, not from consumers' perspective $(n=2)$, and duplicate study $(n=1)$. The flow of study selection was illustrated in Figure 1. As a result, a total of 76 studies were included.

\section{Study Characteristics}

Most of the studies (30/76, 39\%) were conducted in the United States, followed with in the United Kingdom and European countries (15/76, 20\%), Asia (10/76, 13\%), Australia and New Zealand (8/76, 10\%), Canada (8/76, 10\%), Middle-eastern countries (4/76, 5\%), and African countries $(1 / 76,1 \%)$. The majority $(69 / 76,91 \%)$ of the studies was prospective studies compared to retrospective $(7 / 76,9 \%)$. Majority of the studies were questionnaire studies $(53 / 76,70 \%)$, followed with qualitative studies administered through either interview $(13 / 76,17 \%)$, and focus group $(9 / 76,12 \%)$, and both interview and focus group (1/76). In addition, 6 studies were available as abstract only.(Caldentey et al., 2013, David et al., 2012, Ibrahim et al., 2014, Lee et al., 2013, Lowry et al., 2015, Suryani, 2015) The characteristics of studies were summarised in Table 1 with bar-charts illustrations in Appendix S4.

Participants and Nutraceuticals Characteristics

The majority of the studies $(65 / 76,86 \%)$ investigated on general nutraceuticals, compared to only a handful of studies $(11 / 76,14 \%)$ with specific nutraceuticals types. Most of the studies $(39 / 76,51 \%)$ recruited the majority of participants (more than $50 \%$ of participants in the studies) who were nutraceuticals users, followed with majority of participants who were non- 
users of nutraceuticals $(13 / 76,18 \%)$, all participants who were using nutraceuticals $(10 / 76$, $13 \%$ ), nearly half (40-49\% of the participants in the studies) of the participants who were using nutraceuticals $(5 / 76,6 \%)$, and not reported $(9 / 76,12 \%)$.

More than half of the studies $(45 / 76,59 \%)$ did not report about the health condition of the participants, followed with participants with chronic diseases (e.g. chronic kidney disease, diabetes) $(12 / 76,16 \%)$, with life-threatening diseases (e.g. cancer, cystic fibrosis) (12/76, $16 \%)$ and healthy participants $(7 / 76,9 \%)$.

Quality of Studies

For questionnaire studies, almost half of the studies $(25 / 53,48 \%)$ had 0 score for their sample selection method, while $19 / 53(35 \%)$ of the studies had the maximum score of 2 , and with 9/53 (17\%) of the studies scored 1 (Appendix S5). Almost half of the studies (23/53, 43\%) had a representative sample of the target population, while the remaining studies $(30 / 53$, $57 \%$ ) did not justify or did not specify the sampling strategy. Almost half of the studies $(24 / 53,45 \%)$ had a justified sample size or had at least 300 participants,(Comrey and Lee, 2013) while the remaining studies $(29 / 53,55 \%)$ did not justify the sample size used.

For qualitative studies, the overall quality score ranged from 7 to 8 (Appendix S6). More than half of the studies $(14 / 23,61 \%)$ had a statement of ethical approval by an appropriate body, and the remaining studies $(9 / 23,39 \%)$ did not state whether the studies were approved or not. There was no study which described the influence of the researcher either on the research or locating themselves culturally or theoretically.

\section{Factors Affecting Consumers' Decision on The Use of Nutraceuticals}

The factors identified to affect consumers' decision on the use of nutraceuticals were grouped into perceptions of the products, accessibility and source of information summarised in Table 
2. The details of the descriptive themes were summarised in Table $\mathbf{3}$ with the corresponding level of confidence in Table 4 . Coded quotes of primary studies were summarised in Appendix S7.

\section{Perceptions of Nutraceuticals}

\section{Health Benefits}

The perceived health benefits was commonly cited as the reason of taking nutraceuticals (Arvanitoyannis and Krystallis, 2006, Bilici et al., 2012, Blendon et al., 2001, Bruno and Ellis, 2005, Fabian et al., 2011, Hall et al., 2003, Leung and Lum, 2011, Page et al., 2015, Patch et al., 2005, Sinha and Efron, 2005, Tangkiatkumjai et al., 2013, Tangkiatkumjai et al., 2014b, Lim et al., 2006, Milan et al., 2008, Blendon et al., 2013, Chen et al., 2011, Dickinson et al., 2014, Eliason et al., 1999, Jazieh et al., 2004, Kristiansen et al., 2005, Krumbach et al., 1999, Neuhouser et al., 1999, O'Dea and Rawstorne, 2000, Okleshen Peters et al., 2004, Ranelli et al., 1993, Ziegler et al., 2003, Sandmann et al., 2015), while those who doubted the health benefits avoided taking nutraceuticals (Holt et al., 2010, Mercer et al., 2012, Schoenberg et al., 2004, Tangkiatkumjai et al., 2014a, Yoon and Horne, 2004, Arthur et al., 2012, de Jong et al., 2005, Downie et al., 2015, Landström et al., 2009, Nieper, 2005, Niva, 2006, Steele and Senekal, 2005, Tyler et al., 2008, Tyler Jr et al., 2009, Lemay et al., 2011, Klafke et al., 2012). Similarly, knowing about the health benefits of the products was an important factor before deciding to take nutraceuticals (Lee et al., 2013, Williams et al., 2004), while some were curious to find out about the health benefits and decided to take nutraceuticals.(de Guzman et al., 2010) However, the results from clinical evidence may not be as important (Blendon et al., 2013, Blendon et al., 2001). Instead, the experience of those who have used nutraceuticals products may have contributed to the positive perception on the health benefits (Sinha and Efron, 2005). In addition, the perception that nutrients intake from 
diet alone was adequate or not affects the perceived health benefits of taking nutraceuticals. Specifically, those who perceived that nutrients intake was inadequate from diet alone decided to take nutraceuticals (Chen et al., 2011, Dickinson et al., 2014, Eliason et al., 1999, Fabian et al., 2011, Jazieh et al., 2004, Kristiansen et al., 2005, Krumbach et al., 1999, Neuhouser et al., 1999, O'Dea and Rawstorne, 2000, Okleshen Peters et al., 2004, Ranelli et al., 1993, Sandmann et al., 2015, Ziegler et al., 2003), while those who perceived proper diet alone was adequate would not take nutraceuticals (de Jong et al., 2005, Holt et al., 2010, Downie et al., 2015, Nieper, 2005, Niva, 2006, Steele and Senekal, 2005, Tyler et al., 2008, Tyler Jr et al., 2009, Landström et al., 2009).

Consumers with health conditions preferred to try nutraceuticals and hoped that they would be effective (Mercer et al., 2012, Arthur et al., 2012, Klafke et al., 2012, Sinha and Efron, 2005). In addition, taking nutraceuticals together with the medicines they were taking was perceived to enhance therapeutic effectiveness (Bruno and Ellis, 2005, Lim et al., 2006) or relieve side effects of medicines (Hall et al., 2003, Milan et al., 2008). Similarly, consumers who were satisfied with their medicines regime would avoid the use of nutraceuticals (Lemay et al., 2011, Mercer et al., 2012, Tangkiatkumjai et al., 2014a).

\section{Safety}

Similar to health benefits of nutraceuticals products, knowing about the safety of taking nutraceuticals was an important factor for consumers when deciding to take nutraceuticals or not (Arvanitoyannis and Krystallis, 2006, de Jong et al., 2005, Williams et al., 2004, Lee et al., 2013, Mercer et al., 2012). More commonly, consumers had trust in taking nutraceuticals with the belief that it was safe to take nutraceuticals products which motivated the decision to take nutraceuticals (Arthur et al., 2012, Carlisle and Shafir, 2005, David et al., 2012, Eliason et al., 1999, Hök et al., 2011, Ibrahim et al., 2016, Sinha and Efron, 2005, Ortiz and Clauson, 
2006, Nichter and Thompson, 2006, Lowry et al., 2015, Klafke et al., 2012, Mercer et al., 2012, Thompson and Nichter, 2007). Compared to the health benefits, some consumers valued the safety more, with the notion of "if it doesn't help it won't harm" (David et al., 2012, Hök et al., 2011, Klafke et al., 2012). Consumers with concern of potential side effect and drug interaction, on the other hand, avoided taking nutraceuticals (French et al., 2008, Yoon and Horne, 2004, Tyler et al., 2008, Tangkiatkumjai et al., 2014a, Sandmann et al., 2015, Reedy et al., 2005, Downie et al., 2015, Tyler Jr et al., 2009) and preferred normal diet with real (Downie et al., 2015) or organic food (Sandmann et al., 2015).

\section{Other Product Features}

Other product-related features reported to be important for consideration when deciding to take nutraceuticals included the taste of products (Arvanitoyannis and Krystallis, 2006, de Jong et al., 2005, Kristiansen et al., 2005, Niva, 2006, O'Dea and Rawstorne, 2000, Patch et al., 2005, Tyler et al., 2008, Williams et al., 2004), country of manufacture (Patch et al., 2005), packaging (O'Dea and Rawstorne, 2000) and whether if product was manufactured in an environment-friendly way (Arvanitoyannis and Krystallis, 2006).

\section{Accessibility}

Cost

The perceived affordability of nutraceuticals was commonly reported as an important factor for consumers when deciding to take nutraceuticals. When the cost was perceived as high, consumers avoided nutraceuticals (de Jong et al., 2005, Downie et al., 2015, French et al., 2008, Holt et al., 2010, Krumbach et al., 1999, Légaré et al., 2007, Niva, 2006, Patch et al., 2005, Sandmann et al., 2015, Steele and Senekal, 2005, Tyler et al., 2008, Yoon and Horne, 2004). On the other hand, those who perceived that the cost of nutraceuticals was lower than 
conventional medicines were motivated to use nutraceuticals (Gardiner et al., 2007, Ibrahim et al., 2016).

Ease of Using

For consumers who took nutraceuticals, acquiring nutrients from nutraceuticals was seen as easier than from diet (Downie et al., 2015, French et al., 2008, Petróczi et al., 2007). In contrast, if taking nutraceuticals was seen as requiring too much effort (e.g. remembering to take regularly), consumers avoided to take nutraceuticals (Steele and Senekal, 2005, Tyler et al., 2008, Tyler Jr et al., 2009).

\section{Ease of Purchasing}

Consumers also considered about the ease to purchase nutraceuticals products, in terms of the availability of the products, as an important factor when deciding to take nutraceuticals (Williams et al., 2004). It was reported as either a motivating factor (Arvanitoyannis and Krystallis, 2006, Patch et al., 2005, Page et al., 2015) or a barrier (Schoenberg et al., 2004) for consumers to take nutraceuticals.

\section{Source of Information}

\section{Individual's Knowledge}

The perceived level of knowledge regarding nutraceuticals products affected considerably the decision of taking nutraceuticals. The perceived lack of knowledge prevented consumers from taking nutraceuticals (Bilici et al., 2012, Holt et al., 2010, Légaré et al., 2007, Lemay et al., 2011, Nieper, 2005, Niva, 2006, Patch et al., 2005, Reedy et al., 2005, Tyler et al., 2008, Tyler Jr et al., 2009, French et al., 2008), while consumers who perceived they had knowledge about the nutraceuticals products were motivated to take nutraceuticals (Eliason et al., 1999, Vella et al., 2014). In addition, consumers who perceived that lacking knowledge 
on acquiring nutrients from food motivated them to use nutraceuticals instead (Neuhouser et al., 1999).

\section{Healthcare Professional's Consultation}

Healthcare professional's advice regarding the use of nutraceuticals was desired for most consumers, whether it was reported as an important factor when considering to take nutraceuticals (Arcury et al., 2005, Hall et al., 2003, Holt et al., 2010, Lee et al., 2013, Murray et al., 2008, Pally et al., 1984, Patch et al., 2005, Pike et al., 2013, Samuels et al., 2012), the reason of taking (Arranz et al., 2012, Bruno and Ellis, 2005, Klafke et al., 2012, Okleshen Peters et al., 2004, Page et al., 2015, Petróczi et al., 2007, Rausch et al., 2011, Schoenberg et al., 2004, Schultz et al., 2011) and the reason for not taking nutraceuticals (Blendon et al., 2013, Caldentey et al., 2013, Krumbach et al., 1999, Tangkiatkumjai et al., 2014a, Tyler et al., 2008, Tyler Jr et al., 2009, Yoon and Horne, 2004). However, consumers reported healthcare professionals who were close-minded about nutraceuticals prevented discussion about nutraceuticals which prevented consumers from taking nutraceuticals (Légaré et al., 2007).

\section{Influence Other Than Healthcare Professional}

Consumers reported they were motivated by the influence from family and friends to take nutraceuticals (Barnes et al., 2016, Crawford et al., 2010, Krogstad et al., 2007, Miller and Russell, 2004, Nakanishi, 2014, O'Dea and Rawstorne, 2000, Patch et al., 2005, Pike et al., 2013, Suryani, 2015, Tangkiatkumjai et al., 2013), either because there was a family tradition (Ortiz and Clauson, 2006) and culture (Sinha and Efron, 2005) or there was instruction (Barnes et al., 2016, Pike et al., 2013, Suryani, 2015) or recommendation after having good experience (Klafke et al., 2012, Sinha and Efron, 2005). They preferred to trust the advice from those within their social support network (Thompson and Nichter, 2007). In addition, 
consumers may feel pressured if not following their family and friends to take nutraceuticals (Krogstad et al., 2007) while others chose to show care to family and friends through buying nutraceuticals for them (Crawford et al., 2010).

The attitude towards mass media also affected consumers' decision in taking nutraceuticals. Those with positive attitude were motivated to take nutraceuticals after seeing advertisement and lay publication (Arcury et al., 2005) of nutraceuticals (Miller and Russell, 2004, Nakanishi, 2014, Sinha and Efron, 2005), while those with sceptical attitude avoided the use of nutraceuticals (Patch et al., 2005). The recommendation from health store staff (Krogstad et al., 2007) and coach (O'Dea and Rawstorne, 2000, Krumbach et al., 1999) were also reported to motivate the use of nutraceuticals. Last but not least, the influence of religion was also reported to either motivated (Ibrahim et al., 2014, Ibrahim et al., 2016) or prevented (Krumbach et al., 1999) consumers from taking nutraceuticals.

\section{Discussion}

To the extent of our knowledge, this is the first systematic review which summarised all relevant literature to provide an overall picture of the factors affecting consumers' decisions in taking nutraceuticals from consumers' perspective globally. Our review revealed that the health effects and the safety were the two most important product attributes of nutraceuticals for consumers. In other words, consumers believed that taking nutraceuticals caused more health benefit than harm (if any), which explained their intention to take nutraceuticals. In addition, the advice from family and friends and healthcare professionals were crucial in determining the sustained use of nutraceuticals. On the other hand, consumers' lack of belief on the health benefit of nutraceuticals, the high cost of nutraceuticals and their lack of knowledge on nutraceuticals were barriers of using nutraceuticals. 
Ideally, consumers' decision to take nutraceuticals should be informed with clinical evidence. However, clinical evidence was rarely mentioned by consumers as identified in our studies. When it was mentioned, consumers' attitudes were mixed (where they might or might not be affected by the clinical evidence). In fact, consumers are likely to be a lack of access to clinical evidence as well as with limited literacy to interpret the clinical evidence by themselves. This is supported by the findings that most of the consumers in our review recognised themselves to have a lack of knowledge on nutraceuticals. In addition, the lack of understanding on scientific literature may lead to a negative attitude towards clinical evidence (Allum et al., 2008). In turn, consumers are more likely to get information from more convenient resources, for example, friends and family and mass media. More investigation should be conducted on ways to improve how clinical evidence can be reached to the public.

One of the most feasible ways to educate the public regarding the clinical evidence of nutraceuticals was through the consultation with a healthcare professional as consumers as identified in our review were found to value the advice from healthcare professionals regarding nutraceuticals use. However, the optimised utilisation of clinical evidence by healthcare professionals is warranted only if they are well-trained in this area as study has found that healthcare professionals may have limited competency in knowledge and access to reliable clinical evidence regarding CAM (Veziari et al., 2017). In addition to clinical evidence, consumers' preferences should also be taken into account during the discussion with patient as the information from the clinical evidence may be counterintuitive to what consumers have been informed (by family and friends and mass media) (Cohen, 2016, Haynes, 2002).

One of the issues in this review is the heterogeneity which inevitably exists as diverse characteristics of participants and the types of nutraceuticals were included in order to generate a robust understanding on consumers' intention to use nutraceuticals. However, after 
categorising the results according to major population characteristics and (either general or specific) types of nutraceuticals, there was no clear pattern to explain any difference between subgroups. In addition, without the universally accepted criteria for what constitutes "nutraceuticals", the challenge remains on how to categorise one product as either a dietary supplement, functional food or other relevant terms (Lalor and Wall, 2011). Nevertheless, the scope of 'nutraceuticals' is detailed clearly to cover as much relevant products which fulfils its definition as specified in this review without the intention of categorising.

Lastly, despite the exhaustive literature search, there might be other relevant studies that were not indexed in any of the databases covered in this review.

\section{Conclusions}

Consumers considered the health benefits and safety of nutraceuticals as the two most important attributes of nutraceuticals when considering to take nutraceuticals. However, there was a lack of reliable source for consumers to obtain reliable clinical evidence. As recommendations from a healthcare professional is found to be a chief determining factor in the use of nutraceuticals, healthcare professionals should strive to utilise reliable information from clinical evidence to help consumers in making informed decision in using nutraceuticals.

\section{Acknowledgements}

The authors have no conflict of interest to declare.

\section{REFERENCES}

ALLUM, N., STURGIS, P., TABOURAZI, D. \& BRUNTON-SMITH, I. 2008. Science knowledge and attitudes across cultures: A meta-analysis. Public understanding of science, $17,35-54$. 
ARCURY, T. A., BELL, R. A., VITOLINS, M. Z. \& QUANDT, S. A. 2005. Rural older adults' beliefs and behavior related to complementary and alternative medicine use. Complementary Health Practice Review, 10, 33-44.

ARONSON, J. K. 2017. Defining 'nutraceuticals': neither nutritious nor pharmaceutical. British journal of clinical pharmacology, 83, 8-19.

ARRANZ, L. I., CANELA, M. A. \& RAFECAS, M. 2012. Dietary aspects in fibromyalgia patients: Results of a survey on food awareness, allergies, and nutritional supplementation. Rheumatology International, 32, 2615-2621.

ARTHUR, K., BELLIARD, J. C., HARDIN, S. B., KNECHT, K., CHEN, C. S. \& MONTGOMERY, S. 2012. Practices, attitudes, and beliefs associated with complementary and alternative medicine (CAM) use among cancer patients. Integrative Cancer Therapies, 11, 232-242.

ARVANITOYANNIS, I. \& KRYSTALLIS, A. 2006. An empirical examination of the determinants of honey consumption in Romania. International Journal of Food Science and Technology, 41, 1164-1176.

BARNES, K., BALL, L., DESBROW, B., ALSHARAIRI, N. \& AHMED, F. 2016. Consumption and reasons for use of dietary supplements in an Australian university population. Nutrition, 32, 524-530.

BILICI, S., KÖKSAL, E., KÜÇÜKERDÖNMEZ, Ö. \& ŞANLIER, N. 2012. Consumers' kefir consumption: A pilot study in Turkey. HealthMED, 6, 997-1002.

BJELAKOVIC, G., NIKOLOVA, D., SIMONETTI, R. G. \& GLUUD, C. 2004. Antioxidant supplements for prevention of gastrointestinal cancers: a systematic review and metaanalysis. The Lancet, 364, 1219-1228.

BLENDON, R. J., BENSON, J. M., BOTTA, M. D. \& WELDON, K. J. 2013. Users' views of dietary supplements. JAMA Internal Medicine, 173, 74-76.

BLENDON, R. J., DESROCHES, C. M., BENSON, J. M., BRODIE, M. \& ALTMAN, D. E. 2001. Americans' views on the use and regulation of dietary supplements. Archives of Internal Medicine, 161, 805-810.

BRUNO, J. J. \& ELLIS, J. J. 2005. Herbal use among US elderly: 2002 National Health Interview Survey. Annals of Pharmacotherapy, 39, 643-648.

CALDENTEY, J., DEVINS, D., LOPEZ, S., SINVANI, L. D., AKERMAN, M., NOURYAN, C. N., PEKMEZARIS, R. \& WOLF-KLEIN, G. 2013. Driving forces for vitamin and dietary supplement use in geriatric patients. Journal of the American Geriatrics Society, 61, S67-S68.

CARLISLE, E. \& SHAFIR, E. 2005. Heuristics and biases in attitudes towards herbal medicines. The shape of reason: Essays in honour of Paolo Legrenzi., 205-224.

CHEN, S. Y., LIN, J. R., CHEN, T. H., GUO, S. G., KAO, M. D. \& PAN, W. H. 2011. Dietary supplements usage among elderly Taiwanese during 2005-2008. Asia Pacific Journal of Clinical Nutrition, 20, 327-336.

COHEN, P. A. 2016. The Supplement Paradox: Negligible Benefits, Robust Consumption. Jama, 316, 1453-1454.

COMREY, A. L. \& LEE, H. B. 2013. A first course in factor analysis, Psychology Press.

CRAWFORD, P., BROWN, B., NERLICH, B. \& KOTEYKO, N. 2010. Nutritional altruism and functional food: Lay discourses on probiotics. Sociology of Health and Illness, 32, 745-760.

DAVID, T., PIERRE-ANDRE, M. \& PIERRE- YVES, R. 2012. Dietary supplementation-an ignored time bomb? European Journal of Integrative Medicine, 4, 168.

DE GUZMAN, A. B., CORPUZ, J. Q., CREENCIA, J. R., CRISOSTOMO, M. J. S. \& CRISTOBAL, D. J. G. 2010. Information overload or information under siege: 
Filipino faculty extendees' concept, motivation and expectations. Educational Gerontology, 36, 155-170.

DE JONG, N., MEYNEN, E., BRUG, J., BLEEKER, J. K. \& OCKE, M. C. 2005.

Psychosocial Determinants of Functional Food Use: Results of a Qualitative Study.

Trends in lifestyle and health., 141-161.

DICKINSON, A., BLATMAN, J., EL-DASH, N. \& FRANCO, J. C. 2014. Consumer Usage and Reasons for Using Dietary Supplements: Report of a Series of Surveys. Journal of the American College of Nutrition, 33, 176-182.

DOWNIE, L. E., BARRETT, C. \& KELLER, P. R. 2015. The personal nutrition-related attitudes and behaviors of Australian optometrists: Is there evidence for an evidencebased approach? Nutrition, 31, 669-677.

ELIASON, B. C., HUEBNER, J. \& MARCHAND, L. 1999. What physicians can learn from consumers of dietary supplements. Journal of Family Practice, 48, 459-463.

FABIAN, E., TÖSCHER, S., ELMADFA, I. \& PIEBER, T. R. 2011. Use of complementary and alternative medicine supplements in patients with diabetes mellitus. Annals of Nutrition and Metabolism, 58, 101-108.

FRENCH, M. R., VERNACE-INSERRA, F. \& HAWKER, G. A. 2008. A Prospective Study to Identify Factors Affecting Adherence to Recommended Daily Calcium Intake in Women with Low Bone Mineral Density. Journal of the American College of Nutrition, 27, 88-95.

GARCIA-CAZARIN, M. L., WAMBOGO, E. A., REGAN, K. S. \& DAVIS, C. D. 2014. Dietary supplement research portfolio at the NIH, 2009-2011. The Journal of nutrition, 144, 414-418.

GARDINER, P., KEMPER, K. J., LEGEDZA, A. \& PHILLIPS, R. S. 2007. Factors associated with herb and dietary supplement use by young adults in the United States. BMC Complementary and Alternative Medicine, 7.

HALL, J., BISSONETTE, E., BOYD, J. \& THEODORESCU, D. 2003. Motivations and influences on the use of complementary medicine in patients with localized prostate cancer treated with curative intent: results of a pilot study. BJU international, 91, 603607.

HASLER, C., BLOCH, A., THOMSON, C., ENRIONE, E. \& MANNING, C. 2004. Position of the American Dietetic Association: functional foods. Journal of the American Dietetic Association, 104, 814-826.

HAYNES, R. B. 2002. What kind of evidence is it that Evidence-Based Medicine advocates want health care providers and consumers to pay attention to? BMC Health Services Research, 2, 3.

HERZOG, R., ÁLVAREZ-PASQUIN, M. J., DÍAZ, C., DEL BARRIO, J. L., ESTRADA, J. M. \& GIL, Á. 2013. Are healthcare workers' intentions to vaccinate related to their knowledge, beliefs and attitudes? A systematic review. BMC public health, 13, 154.

HÖK, J., FALKENBERG, T. \& TISHELMAN, C. 2011. Lay perspectives on the use of biologically based therapies in the context of cancer: a qualitative study from Sweden. Journal of Clinical Pharmacy \& Therapeutics, 36, 367-375.

HOLT, S., HOLT, A., ERASMUS, P., WATSON, M., FARRELL, T., BLACKSHAW, G., POPPE, M., WILLIAMS, M. \& GILBEY, A. 2010. A survey of use and knowledge of vitamins and supplements in the Bay of Plenty, New Zealand. New Zealand Medical Journal, 123, 114-116.

IBRAHIM, I., HASSALI, M., SALEEM, F. \& AL TUKMAGI, H. 2016. A qualitative insight on complementary and alternative medicines used by hypertensive patients. Journal of Pharmacy and Bioallied Sciences, 8, 284-288. 
IBRAHIM, N. A. R., AL EID, A., AL ALWAN, A., AL GHAWA, Y. \& AL GHALBI, M. 2014a. Abstract only - Pattern of traditional Islamic medicine utilization among adult oncology patients in Saudi Arabia. Journal of Clinical Oncology, 32, no pagination.

IBRAHIM, N. A. R., AL EID, A., AL ALWAN, A., AL GHAWA, Y. \& AL GHALBI, M. 2014b. Pattern of traditional Islamic medicine utilization among adult oncology patients in Saudi Arabia. Journal of Clinical Oncology, 32, no pagination.

JAZIEH, A., KOPP, M., FORAIDA, M., GHOUSE, M., KHALIL, M., SAVIDGE, M. \& SETHURAMAN, G. 2004. The use of dietary supplements by veterans with cancer. Journal of Alternative \& Complementary Medicine, 10, 560-564.

KANTOR, E. D., REHM, C. D., DU, M., WHITE, E. \& GIOVANNUCCI, E. L. 2016. Trends in dietary supplement use among US adults from 1999-2012. Jama, 316, 1464-1474.

KLAFKE, N., ELIOTT, J., OLVER, I. \& WITTERT, G. 2012. Men with cancer using complementary and alternative medicine (CAM): Variations in significant others' involvement. Asia-Pacific Journal of Clinical Oncology, 8, 237.

KRISTIANSEN, M., LEVY-MILNE, R., BARR, S. \& FLINT, A. 2005. Dietary supplement use by varsity athletes at a Canadian University. International Journal of Sport Nutrition and Exercise Metabolism, 15, 195-210.

KROGSTAD, T., NGUYEN, M., WIDING, E. \& TOVERUD, E.-L. 2007. [Children with cancer and their use of natural products]. Bruk av naturpreparater og kosttilskudd hos kreftsyke barn i Norge., 127, 2524-6.

KRUMBACH, C. J., ELLIS, D. R. \& DRISKELL, J. A. 1999. A report of vitamin and mineral supplement use among university athletes in a division I institution. International Journal of Sport Nutrition, 9, 416-425.

KUSZAK, A., HOPP, D., WILLIAMSON, J., BETZ, J. \& SORKIN, B. 2016. Approaches by the US National Institutes of Health to support rigorous scientific research on dietary supplements and natural products. Drug testing and analysis.

LALOR, F. \& WALL, P. G. 2011. Health claims regulations: comparison between USA, Japan and European Union. British Food Journal, 113, 298-313.

LANDSTRÖM, E., HURSTI, U. K. K. \& MAGNUSSON, M. 2009. "Functional foods compensate for an unhealthy lifestyle". Some Swedish consumers' impressions and perceived need of functional foods. Appetite, 53, 34-43.

LEE, K. H., TAN, P. S., LIM, S. G. \& LIM, K. L. 2013. Public perception of drug induced liver injury, herbal and dietary supplements in Singapore. Journal of Gastroenterology and Hepatology, 28, 404-405.

LÉGARÉ, F., STACEY, D., DODIN, S., O'CONNOR, A., RICHER, M., GRIFFITHS, F., LEBLANC, A., ROUSSEAU, J. L. C. \& TAPP, S. 2007. Women's decision making about the use of natural health products at menopause: A needs assessment and patient decision aid. Journal of Alternative and Complementary Medicine, 13, 741749.

LEMAY, J. F., AMIN, A. \& PACAUD, D. 2011. Complementary and alternative medicine use in children and adolescents with type 1 diabetes. Paediatrics and Child Health, $16,468-472$.

LEUNG, S. Y. \& LUM, C. M. 2011. Use of nutritional health supplements and associated factors among parents with children at kindergartens in Hong Kong. Hong Kong Medical Journal, 17, 365-371.

LEWIN, S., GLENTON, C., MUNTHE-KAAS, H., CARLSEN, B., COLVIN, C. J., GÜLMEZOGLU, M., NOYES, J., BOOTH, A., GARSIDE, R. \& RASHIDIAN, A. 2015. Using qualitative evidence in decision making for health and social 
interventions: an approach to assess confidence in findings from qualitative evidence syntheses (GRADE-CERQual). PLoS Medicine, 12, e1001895.

LIM, J., WONG, M., CHAN, M. Y., TAN, A. M., RAJALINGAM, V., LIM, L. P. N., LOU, J. \& TAN, C. L. 2006. Use of complementary and alternative medicine in paediatric oncology patients in Singapore. Annals of the Academy of Medicine Singapore, 35, 753-758.

LIPPMAN, S. M., KLEIN, E. A., GOODMAN, P. J., LUCIA, M. S., THOMPSON, I. M., FORD, L. G., PARNES, H. L., MINASIAN, L. M., GAZIANO, J. M. \& HARTLINE, J. A. 2009. Effect of selenium and vitamin E on risk of prostate cancer and other cancers: the Selenium and Vitamin E Cancer Prevention Trial (SELECT). Jama, 301, $39-51$.

LOCKWOOD, C., MUNN, Z. \& PORRITT, K. 2015. Qualitative research synthesis: methodological guidance for systematic reviewers utilizing meta-aggregation. International journal of evidence-based healthcare, 13, 179-187.

LOWRY, S. A., ALAUNYTE, I. \& AMIRABDOLLAHIAN, F. 2015. Diet quality, usage and perceived benefits of nutritional supplements in young healthy adults. Proceedings of the Nutrition Society, 74, no pagination.

MERCER, M., BRINICH, M. A., GELLER, G., HARRISON, K., HIGHLAND, J., JAMES, K., MARSHALL, P., MCCORMICK, J. B., TILBURT, J., ACHKAR, J. P., FARRELL, R. M., SHARP, R. R., MERCER, M., BRINICH, M. A., GELLER, G., HARRISON, K., HIGHLAND, J., JAMES, K., MARSHALL, P. \& MCCORMICK, J. B. 2012. How patients view probiotics: findings from a multicenter study of patients with inflammatory bowel disease and irritable bowel syndrome. Journal of Clinical Gastroenterology, 46, 138-144.

MILAN, F. B., ARNSTEN, J. H., KLEIN, R. S., SCHOENBAUM, E. E., MOSKALEVA, G., BUONO, D. \& WEBBER, M. P. 2008. Use of complementary and alternative medicine in inner-city persons with or at risk for HIV infection. AIDS Patient Care and STDs, 22, 811-816.

MILLER, C. K. \& RUSSELL, T. 2004. Knowledge of dietary supplement label information among female supplement users. Patient Education and Counseling, 52, 291-296.

MOGENDI, J. B., DE STEUR, H., GELLYNCK, X. \& MAKOKHA, A. 2016. Consumer evaluation of food with nutritional benefits: a systematic review and narrative synthesis. International journal of food sciences and nutrition, 67, 355-371.

MURRAY, K. L., LEE, C. K., MOGAYZEL, P. J., JR., ZEITLIN, P. L. \& ROSENSTEIN, B. J. 2008. Dietary supplement use in pediatric patients with cystic fibrosis. American Journal of Health-System Pharmacy, 65, 562-565.

NAKANISHI, N. 2014. A study of factors associated with dietary supplement consumption in menopausal women. Journal of Nara Medical Association, 65, 39-49.

NEUHOUSER, M. L., PATTERSON, R. E. \& LEVY, L. 1999. Motivations for using vitamin and mineral supplements. Journal of the American Dietetic Association, 99, 851-4.

NEUHOUSER, M. L., WASSERTHEIL-SMOLLER, S., THOMSON, C., ARAGAKI, A., ANDERSON, G. L., MANSON, J. E., PATTERSON, R. E., ROHAN, T. E., VAN HORN, L. \& SHIKANY, J. M. 2009. Multivitamin use and risk of cancer and cardiovascular disease in the Women's Health Initiative cohorts. Archives of internal medicine, 169, 294-304.

NICHTER, M. \& THOMPSON, J. J. 2006. For my wellness, not just my illness: North Americans' use of dietary supplements. Culture, Medicine and Psychiatry, 30, 175222. 
NIEPER, A. 2005. Nutritional supplement practices in UK junior national track and field athletes. British journal of sports medicine, 39, 645-9.

NIVA, M. 2006. Can we predict who adopts health-promoting foods? Users of functional foods in Finland. Scandinavian Journal of Food and Nutrition, 50, 13-24.

O'DEA, J. \& RAWSTORNE, P. 2000. Consumption of dietary supplements and energy drinks by schoolchildren [1]. Medical Journal of Australia, 173, 389.

OKLESHEN PETERS, C. L., SHELTON, J. \& SHARMA, P. 2004. An investigation of factors that influence the consumption of dietary supplements. Health marketing quarterly, 21, 113-135.

ORTIZ, B. I. \& CLAUSON, K. A. 2006. Use of herbs and herbal products by Hispanics in South Florida. Journal of the American Pharmacists Association, 46, 161-167.

PAGE, S. A., MBADIWE, C., MCMORLAND, D. G. \& GROD, J. P. 2015. An exploratory, descriptive study of consumer opinions and behaviors regarding health products sales at 4 chiropractic practices in a large, western Canadian urban center. Journal of Manipulative and Physiological Therapeutics, 38, 59-64.

PALLY, A., SOBAL, J. \& MUNCIE JR, H. L. 1984. Nutritional supplement utilization in an urban family practice center. Journal of Family Practice, 18, 249-253.

PATCH, C. S., TAPSELL, L. C. \& WILLIAMS, P. G. 2005. Overweight consumers' salient beliefs on omega-3-enriched functional foods in Australia's Illawarra region. Journal of Nutrition Education and Behavior, 37, 83-89.

PETRÓCZI, A., NAUGHTON, D. P., MAZANOV, J., HOLLOWAY, A. \& BINGHAM, J. 2007. Limited agreement exists between rationale and practice in athletes' supplement use for maintenance of health: A retrospective study. Nutrition Journal, 6.

PIKE, A., ETCHEGARY, H., GODWIN, M., MCCRATE, F., CRELLIN, J., MATHEWS, M., LAW, R., NEWHOOK, L. A. \& KINDEN, J. 2013. Use of natural health products in children: Qualitative analysis of parents' experiences. Canadian Family Physician, 59, e372-e378.

RANELLI, P. L., DICKERSON, R. N. \& WHITE, K. G. 1993. Use of vitamin and mineral supplements by pharmacy students. American Journal of Hospital Pharmacy, 50, 674-678.

RAUSCH, S. M., WINEGARDNER, F., KRUK, K. M., PHATAK, V., WAHNERROEDLER, D. L., BAUER, B. \& VINCENT, A. 2011. Complementary and alternative medicine: Use and disclosure in radiation oncology community practice. Supportive Care in Cancer, 19, 521-529.

RAUTIAINEN, S., MANSON, J. E., LICHTENSTEIN, A. H. \& SESSO, H. D. 2016 a. Dietary supplements and disease prevention--a global overview. Nature Reviews Endocrinology, 12, 407-421.

RAUTIAINEN, S., MANSON, J. E., LICHTENSTEIN, A. H. \& SESSO, H. D. 2016 b. Dietary supplements and disease prevention [mdash] a global overview. Nature Reviews Endocrinology.

REEDY, J., HAINES, P. S., STECKLER, A. \& CAMPBELL, M. K. 2005. Qualitative comparison of dietary choices and dietary supplement use among older adults with and without a history of colorectal cancer. Journal of Nutrition Education and Behavior, 37, 252-258.

SAMUELS, N., ZISK-RONY, R. Y., ZEVIN, S., BECKER, E. L., YINNON, A. M. \& OBERBAUM, M. 2012. Use of non-vitamin, non-mineral (NVNM) supplements by hospitalized internal medicine patients and doctor-patient communication. Patient education and counseling, 89, 392-398. 
SANDMANN, A., BROWN, J., MAU, G., SAUR, M., AMLING, M. \& BARVENCIK, F. 2015. Acceptance of vitamin D-fortified products in Germany - A representative consumer survey. Food Quality and Preference, 43, 53-62.

SCHOENBERG, N. E., STOLLER, E. P., KART, C. S., PERZYNSKI, A. \& CHAPLESKI, E. E. 2004. Complementary and alternative medicine use among a multiethnic sample of older adults with diabetes. Journal of Alternative \& Complementary Medicine, 10, 1061-1066.

SCHULTZ, M., BARANCHI, A., THURSTON, L., YU, Y. C., WANG, L., CHEN, J., SAPSFORD, M., CHUNG, J., BINSADIQ, M. \& CRAIG, L. 2011. Consumer demographics and expectations of probiotic therapy in New Zealand: results of a large telephone survey. The New Zealand Medical Journal (Online), 124.

SHELTON, R. C., KELLER, M. B., GELENBERG, A., DUNNER, D. L., HIRSCHFELD, R., THASE, M. E., RUSSELL, J., LYDIARD, R. B., CRITS-CHRISTOPH, P. \& GALLOP, R. 2001. Effectiveness of St John's wort in major depression: a randomized controlled trial. Jama, 285, 1978-1986.

SINHA, D. \& EFRON, D. 2005. Complementary and alternative medicine use in children with attention deficit hyperactivity disorder. Journal of Paediatrics and Child Health, 41, 23-26.

STARR, R. R. 2015. Too little, too late: ineffective regulation of dietary supplements in the United States. American journal of public health, 105, 478-485.

STEELE, M. \& SENEKAL, M. 2005. Dietary supplement use and associated factors among university students. South African Journal of Clinical Nutrition, 18, 17-30.

SURYANI, Y. 2015. Survey on self-medication of vitamin and supplement among medical undergraduate students in Yogyakarta, Indonesia. Pharmacoepidemiology and Drug Safety, 24, 387-388.

TANGKIATKUMJAI, M., BOARDMAN, H., PRADITPORNSILPA, K. \& WALKER, D.M. 2014a. Reasons why Thai patients with chronic kidney disease use or do not use herbal and dietary supplements. BMC complementary and alternative medicine, 14, 473.

TANGKIATKUMJAI, M., BOARDMAN, H., PRADITPORNSILPA, K. \& WALKER, D. M. 2013. Prevalence of herbal and dietary supplement usage in Thai outpatients with chronic kidney disease: A cross-sectional survey. BMC Complementary and Alternative Medicine, 13.

TANGKIATKUMJAI, M., BOARDMAN, H. \& WALKER, D.-M. 2014b. Herbal and dietary supplement use in Bangkok: a survey. Journal of Complementary and Integrative Medicine, 11, 203-211.

TANVETYANON, T. \& BEPLER, G. 2008. Beta - carotene in multivitamins and the possible risk of lung cancer among smokers versus former smokers. Cancer, 113, 150-157.

THE FOUNDATION FOR INNOVATIVE MEDICINE 1992. The nutraceuticals initiative: a proposal for economic and regulatory reform. Food Technology, 6, 77.

THOMAS, J. \& HARDEN, A. 2008. Methods for the thematic synthesis of qualitative research in systematic reviews. BMC medical research methodology, 8, 45.

THOMPSON, J. J. \& NICHTER, M. 2007. The compliance paradox: What we need to know about "real-world" dietary supplement use in the United States. Alternative Therapies in Health and Medicine, 13, 48-55.

TONG, A., FLEMMING, K., MCINNES, E., OLIVER, S. \& CRAIG, J. 2012. Enhancing transparency in reporting the synthesis of qualitative research: ENTREQ. BMC medical research methodology, 12, 181. 
TURNER, R. B., BAUER, R., WOELKART, K., HULSEY, T. C. \& GANGEMI, J. D. 2005. An evaluation of Echinacea angustifolia in experimental rhinovirus infections. New England Journal of Medicine, 353, 341-348.

TYLER, C. V., WERNER, J. J., PANAITE, V., SNYDER, S. M., FORD, D. B., CONWAY, J. L., YOUNG, C. W., POWELL, B. L., SMOLAK, M. J. \& ZYZANSKI, S. J. 2008. Barriers to supplemental calcium use among women in suburban family practice: A report from the Cleveland Clinic Ambulatory Research Network (CleAR-eN). Journal of the American Board of Family Medicine, 21, 293-299.

TYLER JR, C. V., ZYZANSKI, S. J., BERKLEY, M. \& PANAITE, V. 2009. Calcium supplement use by African American women. Journal of the National Medical Association, 101, 588-592.

U.S. FOOD AND DRUG ADMINISTRATION. 2015. What is a dietary supplement? [Online]. FDA. Available:

http://www.fda.gov/AboutFDA/Transparency/Basics/ucm195635.htm [Accessed].

VELLA, M. N., STRATTON, L. M., SHEESHKA, J. \& DUNCAN, A. M. 2014. Functional food awareness and perceptions in relation to information sources in older adults. Nutrition Journal, 13.

VEZIARI, Y., LEACH, M. J. \& KUMAR, S. 2017. Barriers to the conduct and application of research in complementary and alternative medicine: a systematic review. $B M C$ complementary and alternative medicine, 17, 166.

WILLIAMS, E., STEWART-KNOX, B. \& ROWLAND, I. 2004. A qualitative analysis of consumer perceptions of mood, food and mood-enhancing functional foods. Journal of Nutraceuticals, Functional and Medical Foods, 4, 61-83.

YOON, S. L. \& HORNE, C. H. 2004. Holistic health care. Perceived health promotion practice by older women: use of herbal products. Journal of Gerontological Nursing, 30, 9-15.

ZIEGLER, P. J., NELSON, J. A. \& JONNALAGADDA, S. S. 2003. Use of dietary supplements by elite figure skaters. International Journal of Sport Nutrition and Exercise Metabolism, 13, 266-276. 